\title{
Simulation of Thermal Stratification and Salinity Using the Ce-Qual-W2 Model (Case Study: Mamloo Dam)
}

\author{
Ramtin Sabeti \\ Dpt of Water Resources Engineering \\ and Management, Islamic Azad \\ University, Central Tehran Branch \\ Tehran, Iran
}

\author{
Saeed Jamali \\ Group of Water Engineering and \\ Hydraulic Structure, Faculty of Civil \\ Engineering, Islamic Azad \\ University, Central Tehran Branch \\ Tehran, Iran
}

\author{
Houman Hajikandi Jamali \\ Group of Water Engineering and \\ Hydraulic Structure, Faculty of Civil \\ Engineering, Islamic Azad \\ University, Central Tehran Branch \\ Tehran, Iran
}

\begin{abstract}
Due to the shortage of fresh water, the quality of stored water in reservoirs has become increasingly important. Thermal regime and salinity are factors that affect the quality of water reservoirs. These two parameters were studied in Mamloo Dam in Tehran province. This dam has recently started to be uses as a source of drinking water for Tehran and thus its water quality is of increased importance. In this regard, the hydrodynamic model for 2014 to 2015 was built and calibrated by the CE-QUAL-W2 model and the model was used to simulate the thermal regime and salinity up to 2020 . Two main scenarios were studied in this period, the continuation of the current situation or a $2.5 \%$ increase in water requirements and $5 \%$ decrease in discharge. The results show that the reservoir will experience thermal stratification in the summer and vertical mixing in the winter. Dased on these results Mamloo reservoir is in branch of warm Monomictic lake. Also results showed that thermal stratification and ssalinity stratification dominates simultaneity. Besides this issue with $2.5 \%$ increase in water requirements and $5 \%$ decrease in discharge, duration of summer thermal stratification will decrease although intensity of thermal stratification will increase.
\end{abstract}

Keywords-Thermal stratification; salinity; CE-QUAL-W2 model; Mamloo reservoir

\section{INTRODUCTION}

Lakes and reservoirs are among the important resources of surface water. Laminar flow in these resources leads to their stratification and slow movement. Thermal regime in water quality models is important in two senses. Firstly, temperature has a direct effect on the chemical reaction rate. Secondly, thermal equilibrium has a great effect on mixing in fresh water systems [1]. Thermal regime of the lakes is mainly the result of interaction between two processes of heat transfer at the lake surface and the effect of gravity on density difference. Depending on the season, heat exchange at the interface of surface lake and the atmosphere leads to an increase or decrease in the temperature of water surface, which is caused by factors such as the amount of energy of the sun, air temperature, relative humidity, wind velocity, and percentage of sky cloud [2]. The wind blowing on the lake surface results in mixing of the surface part of the water and transfer of heat and momentum to the lower part. A buoyancy force exists against mixing, which prevents further mixing. This force is created by the density difference at different temperatures and causes the denser part of the water to be positioned at lower parts [3]. In the reservoirs and lakes of high length, using the averaged $2 \mathrm{D}$ model in the width is inevitable for accurate prediction of thermal stratification and water quality. A suitable and accurate method in 2D modeling is simultaneous modeling of the flow and qualitative parameters. Fluid flow modeling is performed using the mass, momentum, and energy conservation equations. In many turbulent flows, the Reynolds equations modeling the averaged 3D turbulent fluid flow in time can be used. Furthermore, mathematical models are developed depending on the spatial and temporal changes, the factors influencing the conditions of aquatic ecosystems, especially dam reservoirs [4]. Selecting a model consistent with the conditions and effective factors, as well as the available information and data, is one of the fundamental steps in mathematical simulation of aquatic ecosystems, namely dam reservoirs. CE-QUAL-W2 software is a 2D model (horizontal and vertical) for water quality and hydrodynamic, which can model structures such as deep rivers, dam reservoir, lakes, and estuaries. This model was developed in 1995 by Water Estuary Studies (WES) of the engineers of US Army, and works based on solving non-permanent, $2 \mathrm{D}$, hydrodynamic, and dispersion equations [5]. In this study, the thermal stratification and salinity of Mamloo Dam reservoir is modeled using the 3.7 version of this software introduced in 2012.

\section{THE STUDIED REGION}

Mamloo Dam reservoir is located on Jajrood River, about $45 \mathrm{~km}$ from east of Tehran. The studied region is located between 32-35 northern latitude and 38-52 eastern longitude of the equator, which is a part of Tehran Province regarding the divisions of the country [6]. The purpose of building this dam was to take advantage of the capacity of catchment area of Jajrood River and supply the agricultural water of Varamin and Pakdasht and part of the need for drinking water in Tehran. 
Dam operations started in August 2002 and ended in 2010. The type of dam is soiled with clay core and ogee spillway, $89 \mathrm{~m}$ height from foundation, $27 \mathrm{~m}$ width in the foundation, and 10 $\mathrm{m}$ width in the dam crest. Reservoir volume is $250 \mathrm{~m}^{3}$, the lake area is 620 acres, and the lake length is $8500 \mathrm{~m} \mathrm{[7].} \mathrm{The}$ concentration of different qualitative parameters in the reservoir changes with the input concentration and thermal stratification in depth. The TDS (Total Dissolved Solid) concentration is usually higher in the lower layers than the upper layers. The project of water supply from Mamloo Dam to Tehran City for drinking and domestic usage has been implemented during recent years, and has added to the importance of the water quality of this reservoir. Given the issues discussed above, studying the salinity and thermal regime of Mamloo Dam reservoir is an important step in controlling its water quality.

\section{MODEL DEVELOPMENT}

The input information required for simulating temperature and salinity in the software are: simplified dimensions of the reservoir, meteorological information (air temperature, dew point, wind direction and velocity, cloud cover), input and output flow rates, temperature of input flows, water temperature in depth, TDS at different times and depth intervals, hydraulic conductivity of lateral branches, and boundary conditions [8]. The geometrical shape of Mamloo Dam reservoir was divided into a primary branch with 21 longitudinal elements, each having $200 \mathrm{~m}$ length, by 1:10,000 maps provided by Tehran Regional Water Organization. Reservoir depth was also divided into 37 elements of 1,2 , and $3 \mathrm{~m}$ depth. Figure 1 shows a view of the geometrical model of Mamloo Sam reservoir.

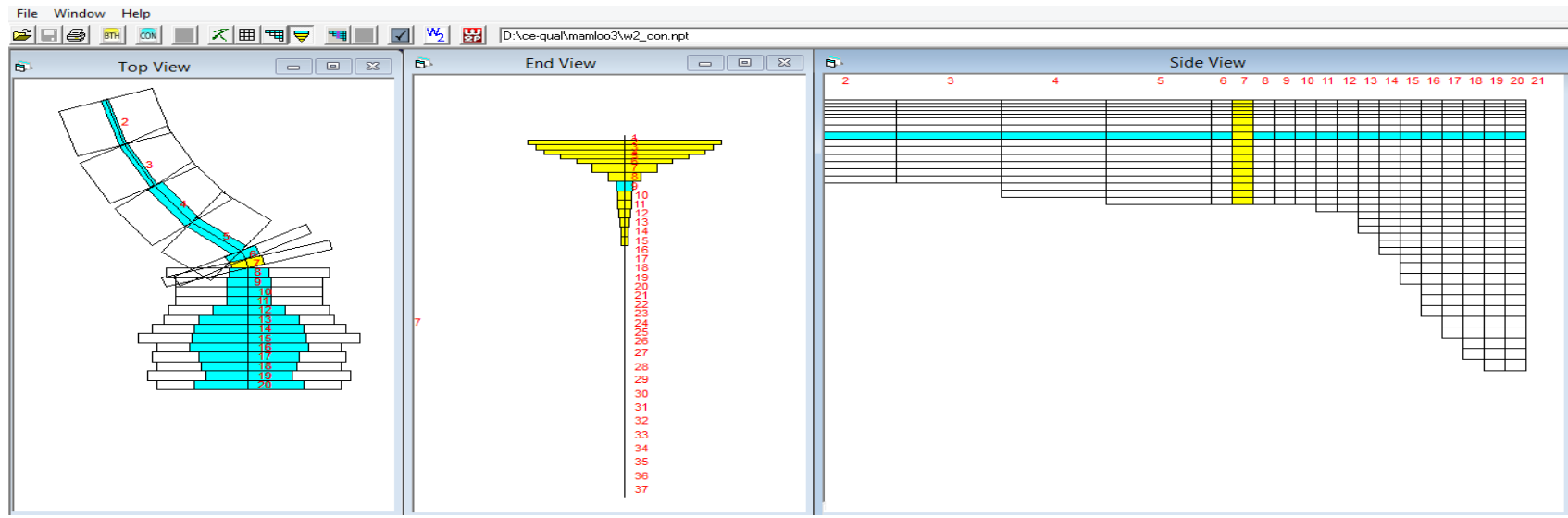

Fig. 1. A view of the geometry of Mamloo Dam reservoir in CE-QUAL-W2 software

The output spillway level of this reservoir is $1,224 \mathrm{~m}$ from sea level, and the minimum production level is $1,169 \mathrm{~m}$ from the sea level. This data was also fed to the model. To develop the model, the water year data from 2014 to 2015, taken from Tehran Regional Water Organization, were used, and the hydrodynamic model was developed. Calibration of the hydrodynamic model was done in two steps: The first step was done by matching the volume/height plots obtained by simulation results and the real data of Mamloo Dam. In the second step, the water height obtained by simulation was matched with the real height by controlling the input and output flows of the reservoir. Qualitative calibration also consists of two steps: thermal and salinity calibration. In thermal calibration, first, the most important parameters were specified by performing a sensitivity analysis on the parameters involved in thermal modeling of the reservoir; then, integration of simulation results with observations was done by changing the parameters. Table I shows the results of sensitivity analysis with respect to the temperature in Mamloo Dam reservoir. The closer the coefficient of sensitivity of the parameters to 1 , the higher the effect of that parameter. Coefficients less than 0.5 usually have no effect and don't require investigation. This way, the wind impact factor was selected as the most effective parameter in thermal calibration of Mamloo Dam reservoir.
TABLE I. TEMPERATURE SINSITIVITY COEFFICIENT IN THE RESERVOIR WITH RESPECT TO THE CHANGES IN THAT PARAMETER

\begin{tabular}{|c|c|}
\hline Coefficient & The value of impact factor \\
\hline Longitudinal viscosity of eddy & 0.17 \\
\hline Longitudinal dispersion of eddy & 0.21 \\
\hline Chezy or Manning coefficient & 0.05 \\
\hline Wind impact (wind power) & 0.85 \\
\hline Absorption of solar radiation at the surface & 0.13 \\
\hline Light reduction in clean water & 0.17 \\
\hline Light reduction in non-organic solid material & 0.11 \\
\hline Light reduction in organic solid material & 0.07 \\
\hline
\end{tabular}

Simulation of thermal conditions and TDS for future years was performed assuming a continuation of the current situation or a $2.5 \%$ increase in water demand and a $5 \%$ reduction in the amount of water discharge. According to the information of Tehran Regional Water Organization and Meteorological Department, the weather of the region studied was relatively unstable, and its wind impact factor for correcting the effect of wind velocity measurement was far from the dam reservoir, varied from 0.5 to 0.9 for mountain areas and foothills, and equal to 1 for open and flat land. Given the topography of the region, this coefficient was selected to be 0.86 at the beginning of calibration. The above procedure was also used for salinity 
calibration, except that the amount of input TDS, input layer, and overpass and underpass at time of entering the reservoir were evaluated in this stage. Qualitative information of 20142015 water years was used for calibration and validation of the model. The calibrated model was validated land application; thereupon the two qualitative scenarios above were selected for modeling.

\section{DISCUSSION AND CONCLUSION}

In most parts of the world, the surface of lakes and reservoirs passes through a specific temperature cycle during the year. Temperature trend of Mamloo Dam in the reservoir depth, based on the assumptions made regarding continuation of the current situation, $2.5 \%$ increase in water demand, and $5 \%$ decrease in the amount of water discharge, in 2020 is shown in Figure 2 and Figure 3. The main reasons for temperature variation in water depth are thermal contact with the atmosphere and changes in the amount of solar radiation. Heat transfer from the surface to depth is often affected by solar radiation, long wave radiation of the atmosphere, thermal flows associated with evaporation and precipitation, surface and sub-surface inflow and outflow, and thermal contact with the lake bed [9].

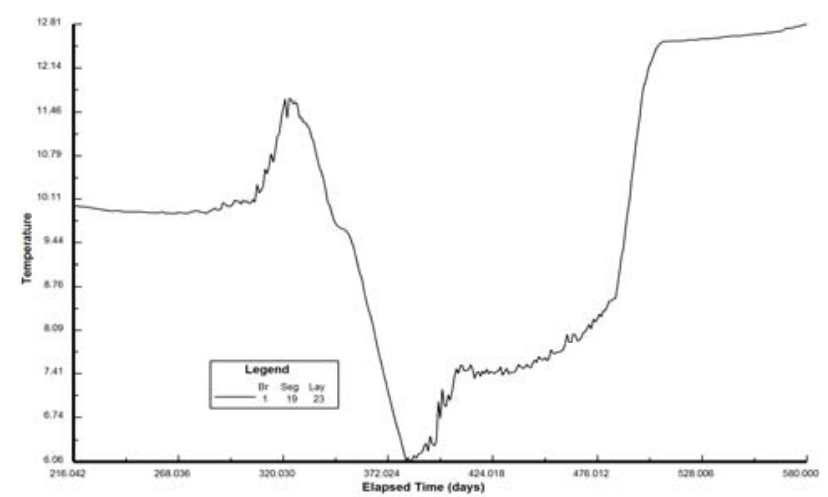

Fig. 2. Temperature variation in Mamloo Dam reservoir depth, assuming continuation of the current situation until 2020

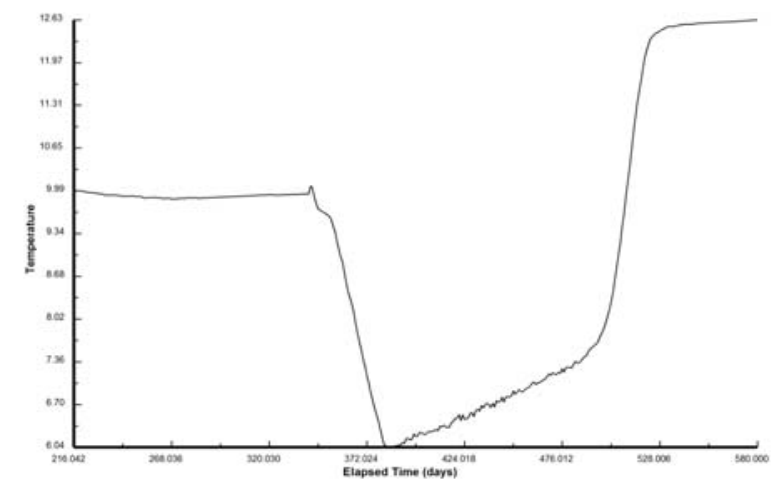

Fig. 3. Temperature variation in Mamloo Dam reservoir depth, assuming a $2.5 \%$ increase in water demand and a $5 \%$ reduction in water discharge until 2020
It is clear from Figure 2 that assuming continuation of the current situation until 2020, temperature difference between superficial and deep layers increases in the time interval from October to April and a thermal stratification forms. The maximum temperature gradient and stratification peak is also observed in summer. After the hot season, the layers at different depths experience thermal mixing and the thermal stratification in the reservoir breaks down. Stratification intensity decreases by cooling the air, and the thermal mixing conditions in the reservoir will be re-achieved in autumn. In case of a $2.5 \%$ increase in water demand and a $5 \%$ reduction in water discharge, as shown in Figure 3, the thermal regime in the reservoir doesn't change, but it increases when the reservoir experiences thermal mixing, following which a reduction in stratification time of the reservoir is observed. Given the numbers of the sluice located at the level close to the bottom of the reservoir, further water exploitation reduces the retention time of deep layers and helps vertical mixing in the reservoir. In other words, further water exploitation brings the reservoir closer to optima; production level in terms of temperature. TDS variation in reservoir depth up to 2020 water is shown in Figure 4 and Figure 5.

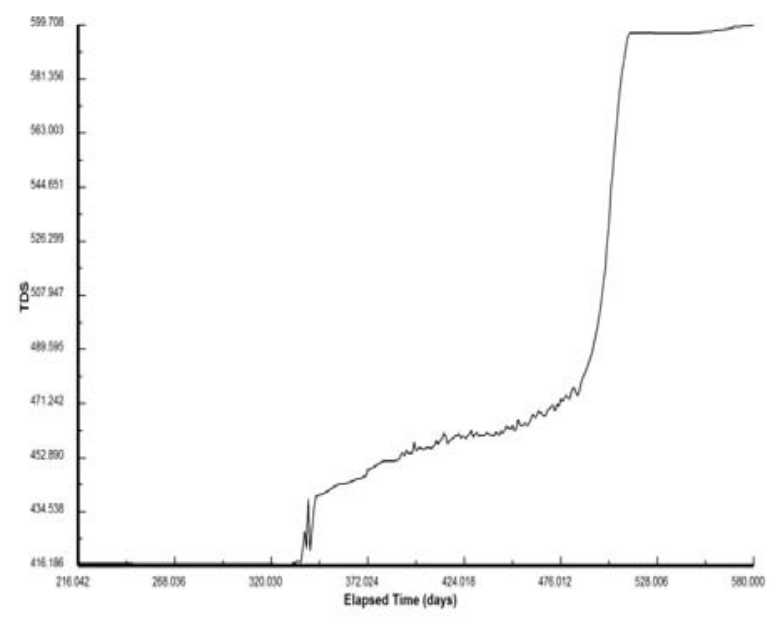

Fig. 4. TDS variation in reservoir depth, assuming continuation of the current situation until 2020

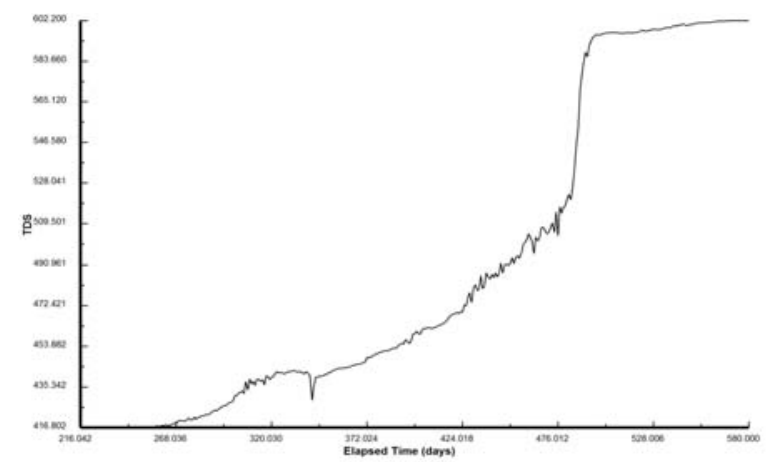

Fig. 5. TDS variation in reservoir depth, assuming a $2.5 \%$ increase in water demand and a 5\% reduction in water discharge until 2020 
Comparing these two figures with Figures 2 and Figure 3 indicates that TDS follows the trend of temperature variation, and a Change in TDS is observed whenever there is any temperature change. However, given the dependency of TDS to the elements dissolved in it, other reactions and the amount of TDS input cannot be evaluated only by temperature profile. Therefore, it can be argued that TDS changes with changing temperature, so that whenever there is a temperature change in the reservoir, changes in TCS concentration will be observed as well. More importantly, an increase in TDS concentration is observed in any part with intensive thermal gradient. Studying the surface temperature variation of different lakes at similar weather conditions, it was found that the average daily temperature of different lakes are similar; there is only a little difference between them in spring. In hot seasons and during summer, smaller lakes tend to absorb heat more quickly [10]. It is the mixing properties of the lake that determines how effectively and to what extent does the temperature transfers vertically to depth. If the surface temperature of dam reservoir exceeds $4^{\circ} \mathrm{C}$, it warms up and becomes less dense, so there is the possibility of mixing up to a more limited depth. This depth depends on the limited energy provided by the wind. In most reservoirs, like Mamloo Dam reservoir, thermal stratification in the summer period starts by starting the density difference. In deep lakes, the thermal stratifications remains until the cold weather of autumn and winter creates a circulation in deep waters. The warmer surface layer of water is called epilimnion, while the lower cooler layers not mixing with the epilimnion during stratification is called hypolimnion. A clear temperature gradient is formed at the interface of these two layers, called thermocline or thermo-layer. In summer stratification conditions, a metalimnion forms between epilimnion and hypolimnion, which connects to these two layers by thermocline. Figure 6 shows these layers in thermal profile of Mamloo Dam reservoir at $50 \mathrm{~m}$ distance from dam crest. The profile of temperature variation in Mamloo Dam reservoir depth for different seasons of the year is shown in Figures 7 and Figure 8. To plot the results, the first day of the last month in each season was taken as indicator of each season. The profiles obtained for autumn and winter show complete thermal mixing at reservoir depth. The surface layer gets warm in autumn and winter by solar radiation and contact with the atmosphere, bit the deeper layers are preserved from the main source of heat.

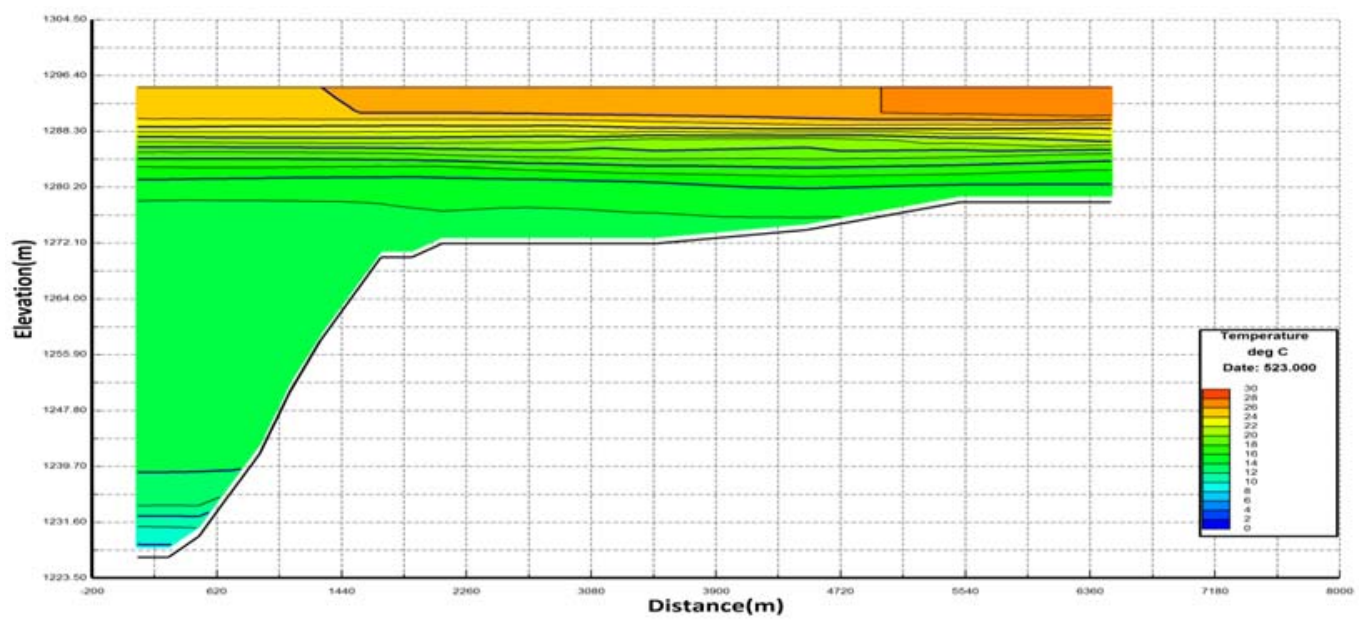

Fig. 6. Thermal stratification formed in summer 2020 in Mamloo Dam reservoir
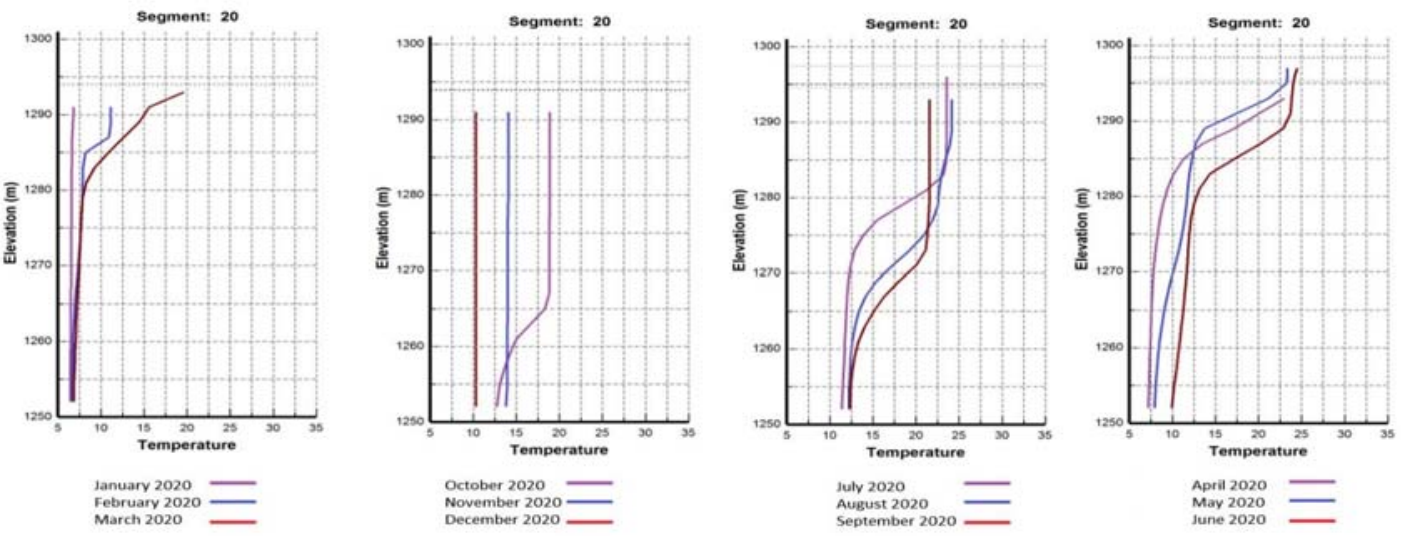

Fig. 7. Temperature profile of Mamloo Dam reservoir in a $100 \mathrm{~m}$ distance from the dam crest during 2020, assuming continuation of the current situation 

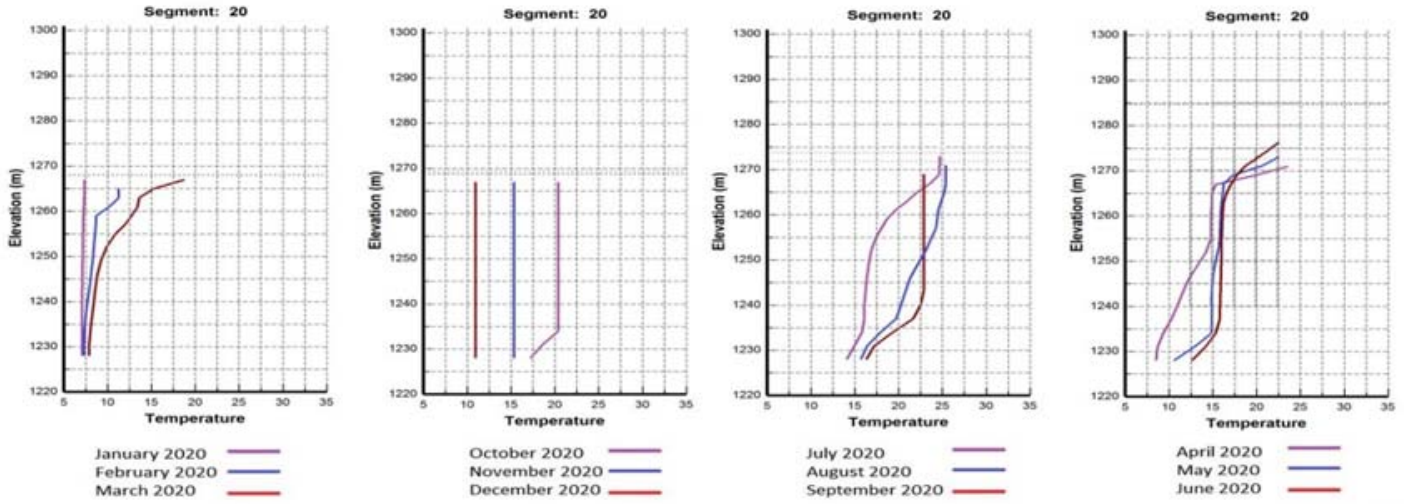

Fig. 8. Temperature profile of Mamloo Dam reservoir in a $100 \mathrm{~m}$ distance from the dam crest during 2020 , assuming a $2.5 \%$ increase in water demand and a $5 \%$ reduction in water discharge

Figure 7 and Figure 8 show that thermal stratification in Mamloo Dam reservoir starts to form at the beginning of spring, and reaches its peak in summer. Epilimnion and atmosphere exchange heat and volatile components such as different gases. This layer randomly rotates and mixes under the influence of wind and climate changes during stratification period. In contrast, the hypolimnion has no interaction with the atmosphere and transfer of the dissolved materials is partially done by the metalimnion and thermo-layer, which have high temperature gradient. In many lakes, only chemical deposition transfers a great deal of materials from the metalimnion. Wind is a decisive factor in the thickness of epilimnion in most of the lakes. In lakes with very low wind velocity, other factors may have the primary role, one example of which is a very clean and transparent lake, in which the light can diffuse to the depth greater than the depth of wind mixing [11]. There are also situations in which gas molecular diffusion is the main factor determining the ice layer thickness at surface of the lake. In Mamloo Dam reservoir, the thickness of epilimnion is not constant during stratification period.

A thin layers forms in spring, which gradually thickens in summer due to the light flow of wind. This situation continues until autumn, when the stratification gradually disappears by the surface cold water. Therefore, identifying simple method for measurement or determination of epilimnion thickness is very useful in the study of water resources. All results proved that Mamloo Dam reservoir is in the category of warm Monomictic lakes. Warm Monomictic lakes are located in low levels and low latitudes, in which the temperature of the lake doesn't exceed $4^{\circ} \mathrm{C}$. in this kind of lakes and reservoirs, thermal stratification is once done in summer and complete mixing is once done in winter. Given the position of our country in terms of altitude and geographical location, most of the dams in the country are located in this region, and most of the reservoirs, especially deep reservoirs, namely Mamloo Dam reservoir, are located in the warm Monomictic region. Figure 9 and Figure 10 show TDS in Mamloo Dam reservoir depth during 2019-2020 water years.

According to TDS profile, assuming continuation of the current situation, TDS variation hasn't significantly changed with respect to the changes in the input, and it preserves the prevailing regime. Assuming a $2.5 \%$ increase in water demand and a $5 \%$ reduction in water discharge, the results indicate that no changes has occurred in this parameter by increasing mixing power of the reservoir. Therefore, the results imply higher dependence of TDS to the input.

Mamloo Dam reservoir experiences one stratification and one complete mixing during a year and fits into the category of warm Monomictic lakes. This type of lakes is located in low levels and low latitudes, in which the average temperature of the lake never exceeds $4^{\circ} \mathrm{C}$ [12]. In this summer, stratification forms in summer and complete mixing occurs in winter. Given the position of our country in terms of altitude and geographical location, most of the dams in the country are locates in this region, and most of the reservoirs, especially deep ones, such as Mamloo Dam reservoir, are located in warm Monomictic region. In hot seasons when there is thermal stratification, TDS also experiences stratification according to similar studies, and it decreases with increasing depth. Thereupon, the necessity of documenting this parameter and investigating the conditions prevailing at the bottom of Mamloo reservoir is of great importance. Assuming continuation of the current situation or a $2.5 \%$ increase in water demand and a $5 \%$ decrease in the amount of water discharge until 2020, this lake will still remain in the category of warm Monomictic lakes.

\section{SugGestions}

Exploiting water from lower lakes of the reservoir helps its vertical mixing and reduces the thickness of hypolimnion and the time required for creation of thermal stratification conditions. Discharging the depositions from the reservoir helps to reduce retention time and thickness of the hypolimnion. Regular qualitative measurements in reservoir surface and depth are an important step in formulating a management pattern suitable for this reservoir. Increasing field studies provides the possibility of long-term prediction of the reservoir conditions prevailing in Mamloo Dam reservoir, and increases the confidence interval of the decisions. It is suggested to use CE-Qual-W2 model in 2D modeling of other reservoirs in Tehran Province, so that an integrated management pattern could be formulated using the results of these studies. 


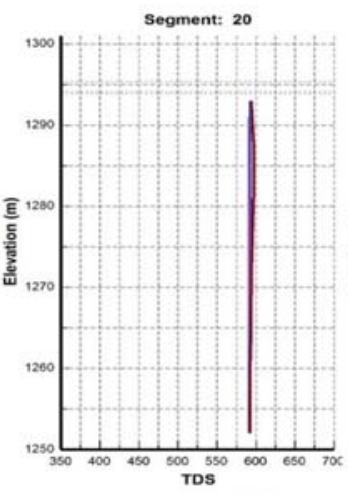

January 2020 February 2020
March 2020

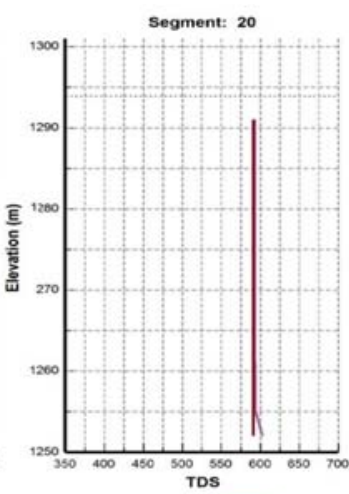

October 2020 November 2020

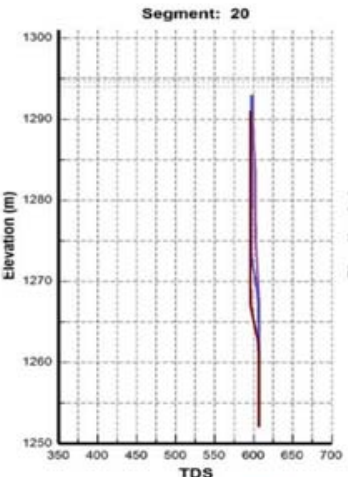

July 2020

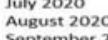

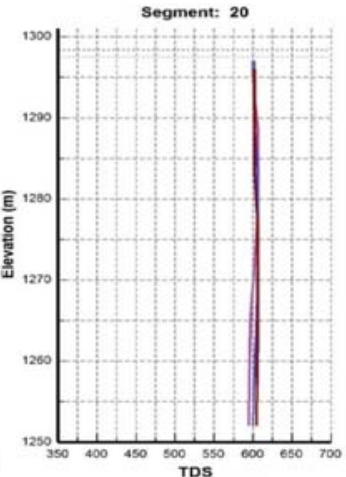

Aprilt2020

May 2020
June 2020

Fig. 9. TDS profile of Mamloo Dam reservoir in a $100 \mathrm{~m}$ distance from the dam crest during 2020, assuming continuation of the current situation

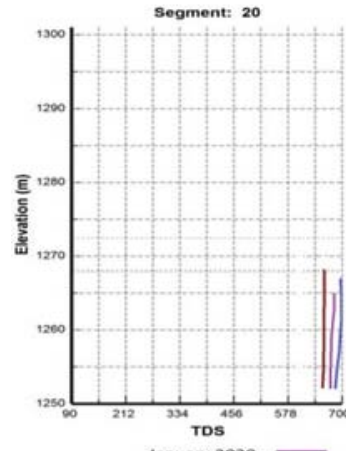

January 2020

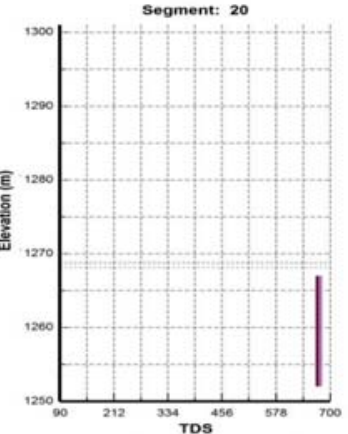

October 2020

November 2020

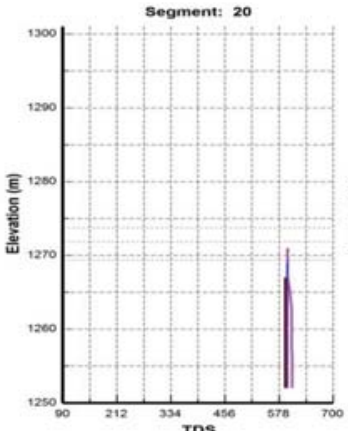

July 2020

August 2020

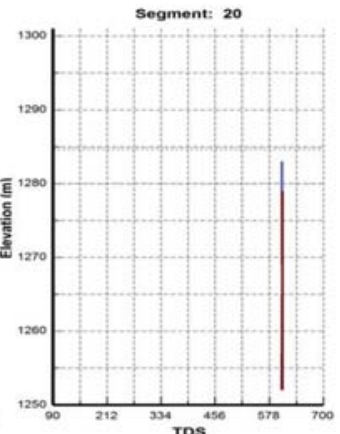

April 2020
May 2020
lyoe 2020

Fig. 10. TDS profile of Mamloo Dam reservoir in a $100 \mathrm{~m}$ distance from the dam crest during 2020, assuming a $2.5 \%$ increase in water demand and a $5 \%$ reduction in water discharge

\section{REFERENCES}

[1] J. Soltani, M. R. Alavi Moghadam, "The effect of thermal stratification on water quality in Iran's dams-An Overview", Proceedings of 8th National Conference of Environmental Health, Tehran, Iran, Vol. 1, No. 1, pp. 8-10, 2005

[2] E. G. Chung, S. G. Schladow, J. Perez-Losada, D. M. Robertson, "A linked hydrodynamic and water quality model for the Salton Sea", Hydrobiologia, Vol. 604, No. 1, pp. 57-75, 2008

[3] B. Klein, W. Roether, B. B. Manca, D. Bregant, V. Beitzel, V. Kovacevic, A. Luchetta, "The large deep water transient in the Eastern Mediterranean", Deep Sea Research Part I: Oceanographic Research Papers, Vol. 46, No. 3, pp. 371-414, 1999

[4] H. Hekmatifar, M. Nazariha, S. Givehchy, "The assessment of Agriculture Damages due to flood by using modeling in ARC View \& HEC-RAS”, Journal of Environmental Science and Technology, Vol. 11, No. 4, pp. 15-20, 2009

[5] T. M. Cole, S. A. Wells, CE-QUAL-W2: A two-dimensional, laterally averaged, hydrodynamic and water quality model, Version 3.7, User Manual, Washington, DC, 2011.

[6] A. G. Behbahani, K. Khoshbakht, A. Davari, L. Tabrizi, H. Veisi, A. Alipour, "Assessing the effect of socio-economic factors on agrobiodiversity in homegardens of Jajrood and Jamabrood in Tehran province (Iran)", Advances in Environmental Biology, Vol. 2, No. 1, pp.1708-1716, 2012

[7] Tehran Regional Water Organization, Water supply project to Tehran, 2010.

[8] Ministry of Power, Guidelines for water quality studies of large reservoirs, Tehran publication, 2010

[9] D. M. Imboden, A. Wüest, "Mixing mechanisms in lakes" in: Physics and Chemistry of Lakes, Springer Berlin Heidelberg, 1995

[10] B. Boehrer, M. Schultze, "Stratification of lakes", Reviews of Geophysics, Vol. 46, No. 2, pp. 10-15, 2008

[11] M. Sicard, C. Pérez, F. Rocadenbosch, J. M. Baldasano, D. GarcíaVizcaino, "Mixed-layer depth determination in the Barcelona coastal area from regular lidar measurements: methods, results and limitations", Boundary-Layer Meteorology, Vol. 119, No. 1, pp. 135-157, 2006

[12] P. R. Kannel, S. R. Kanel, S. Lee, Y. S. Lee, T. Y. Gan, "A review of public domain water quality models for simulating dissolved oxygen in rivers and streams", Environmental Modeling \& Assessment, Vol. 16, No. 2, pp.183-204, 2011 